\title{
Factors of air ion balance in a coniferous forest according to measurements in Hyytiälä, Finland
}

\author{
H. Tammet ${ }^{1}$, U. Hõrrak ${ }^{1,2}$, L. Laakso ${ }^{2}$, and M. Kulmala ${ }^{2}$ \\ ${ }^{1}$ Institute of Environmental Physics, University of Tartu, Ülikooli 18, 50090, Tartu, Estonia \\ ${ }^{2}$ Department of Physical Sciences, University of Helsinki, P.O. Box 64, 00014, Finland \\ Received: 22 December 2005 - Published in Atmos. Chem. Phys. Discuss.: 18 April 2006 \\ Revised: 14 July 2006 - Accepted: 7 August 2006 - Published: 21 August 2006
}

\begin{abstract}
A new mathematical model describing air ion balance was developed and tested. It has improved approximations and includes dry deposition of ions onto the forest canopy. The model leads to an explicit algebraic solution of the balance equations. This allows simple calculation of both the ionization rate and the average charge of aerosol particles from measurements of air ions and aerosol particles, with some parameters of the forest. Charged aerosol particles are distinguished from cluster ions by their size, which exceeds $1.6 \mathrm{~nm}$ diameter. The relative uncertainty of the ionization rate is about the same or less than the relative uncertainties of the measurements. The model was tested with specific air ion measurements carried out simultaneously at two heights at the Hyytiälä forest station, Finland. Earlier studies have shown a difference in the predictions of the ionization rate in the Hyytiälä forest when calculated in two different ways: based on the measurements of the environmental radioactivity and based on the air ion and aerosol measurements. The new model explains the difference as a consequence of neglecting dry deposition of ions in the earlier models. The ionization rate during the $16 \mathrm{~h}$ campaign was $5.6 \pm 0.8 \mathrm{~cm}^{-3} \mathrm{~s}^{-1}$ at the height of $2 \mathrm{~m}$ and $3.9 \pm 0.2 \mathrm{~cm}^{-3} \mathrm{~s}^{-1}$ at the height of $14 \mathrm{~m}$, between the tops of the trees. The difference points out the necessity to consider the height variation when the ionization rate is used as a parameter in studies of ion-induced nucleation. Additional results are some estimates of the parameters of air ion balance. The recombination sink of cluster ions on the ions of opposite polarity made up 9-13\%, the sink on aerosol particles 65-69\%, and the sink on forest canopy $18-26 \%$ of the total sink of cluster ions. The average lifetime of cluster ions was about $130 \mathrm{~s}$ for positive and about $110 \mathrm{~s}$ for negative ions. At the height of $2 \mathrm{~m}$, about $70 \%$ of the space charge of air was carried by aerosol particles, and at the height of $14 \mathrm{~m}$, about $84 \%$.
\end{abstract}

Correspondence to: $\mathrm{H}$. Tammet

(hannes.tammet@ut.ee)

\section{Introduction}

Atmospheric aerosol is an important factor of the Earth's climate. It is very sensitive to the activities of mankind because the genesis of new particles depends on the trace components of the air. Understanding of the mechanisms of the production of new atmospheric aerosol particles is one of the key problems of the atmospheric science (Kulmala, 2003). The role of air ions in particle formation (Svensmark, 1998; Yu and Turco, 2001; Harrison and Carslaw, 2003; Laakso et al., 2004a) is an often-discussed question. However, the existing knowledge is not sufficient for drawing reliable conclusions. An important parameter of the models of ion-induced nucleation (Yu and Turco, 2001; Laakso et al., 2002; Tammet and Kulmala, 2005) is the ionization rate, which is the main factor of the air ion balance. The experimental data about ion-induced nucleation in the atmosphere is very limited (Kulmala et al., 2004). In the traditional research of air ions (e.g. Hõrrak et al., 2003), the air ion concentrations and mobilities are measured, but the ionization rate remains unknown. Thus the improvement of the models of the air ion balance and the methods of measurement of the ionization rate is an important task.

The direct methods of measuring the ionization rate in atmospheric air (Israël, 1970) are simple but troublesome and not applicable in routine environmental monitoring. Careful measurements by Hess (1929) in the clean environment of Helgoland resulted in the values of the atmospheric surface layer ionization rate between 5 and $10 \mathrm{~cm}^{-3} \mathrm{~s}^{-1}$ depending on the meteorological situation. Tuomi (1989) reported average ionization rate of $6.6 \mathrm{~cm}^{-3} \mathrm{~s}^{-1}$ in a suburb of Helsinki, Finland, for the ten-year period 1977-1986. According to the existing knowledge (Israël, 1970), a component of the surface layer ionization rate of about $2 \mathrm{~cm}^{-3} \mathrm{~s}^{-1}$ is caused by cosmic rays and the rest in about equal shares by the internal ionizing radiation of airborne radioactive substances (radon, thoron and their progeny) and the external ionizing radiation from the radioactive substances contained in the ground.

Published by Copernicus GmbH on behalf of the European Geosciences Union. 
Information about air ions and the ionization rate is especially required in experiments intended to understand the full complex of processes of new particle formation in the atmosphere. A well-known site of systematic atmospheric nucleation studies is the SMEAR-II research station in Hyytiälä, Finland (Kulmala et al., 2001, 2004), where air ions and aerosol are continuously monitored. The measurement station in Hyytiälä is located in a Scots pine forest and the ground around it is igneous bedrock partially open but mostly covered with a thin layer of soil.

Laakso et al. (2004b) analyzed the measurements of air ions, aerosol, radon and ionizing radiation made in Hyytiälä during 20 March-11 April 2003. They calculated the average ionization rate according to the measurements of ionizing radiation and radon activity to be $4.5 \mathrm{~cm}^{-3} \mathrm{~s}^{-1}$, but according to the measurements of air ion mobility distribution and aerosol particle size distribution, it was only $2.6 \mathrm{~cm}^{-3} \mathrm{~s}^{-1}$. The conflict of the results was explained by probable underestimating of the sinks of air ions. Actually, Laakso et al. (2004b) neglected dry deposition and underestimated the mobility of ions. Hõrrak et al. (2005) analyzed the air ion and aerosol measurements made in Hyytiälä during 31 March-29 April 1999. The average ionization rate calculated from the equation of the air ion balance was $2.8 \mathrm{~cm}^{-3} \mathrm{~s}^{-1}$. The classic model of air ion balance (Israël, 1970) was used in both studies. This model includes the sinks of cluster ions due to the recombination and attachment to the aerosol particles but does not consider the dry deposition onto surfaces. Hõrrak et al. (2005) added a constant extra ion sink into the equation of the air ion balance and found that the extra sink of $0.0052 \mathrm{~s}^{-1}$ assures the best fit of the measurements. If the extra sink was included into the equation of the air ion balance, then an increased estimate of the ionization rate of $4.8 \mathrm{~cm}^{-3} \mathrm{~s}^{-1}$ was found. It was assumed that the extra sink could be caused by deposition of air ions in the coniferous forest described by Tammet and Kimmel (1998) and Tammet et al. (2001).

The low values of the ionization rate calculated from the air ion measurements have raised unanswered questions about sources and sinks of air ions and about applicability of the simplified equation of the air ion balance used by Laakso et al. (2004b) and Hõrrak et al. (2005) for interpretation of the measurements made in coniferous forest. In the present paper the air ion balance is considered according to the improved model by Tammet and Kulmala (2005), which takes into account different properties of positive and negative ions, and the space charge carried by aerosol particles. Additionally, the air ion sink due to the dry deposition of ions on the forest canopy is included into the model. The model is tested on the basis of special measurements carried out at the two heights from the ground of $2 \mathrm{~m}$ and $14 \mathrm{~m}$.

The applications of the proposed model are limited by simplifications, which are allowed in case of considered test measurements but can raise complications in unlike situations. An important simplification is distinction of the class of cluster ions often called the small ions and description of cluster ions with only four parameters: the concentrations and the mean mobilities of positive and negative ions. This is acceptable during the periods without nucleation bursts when the air ion mobility distribution has a deep minimum around the value of $0.5 \mathrm{~cm}^{2} \mathrm{~V}^{-1} \mathrm{~s}^{-1}$ (Hõrrak et al., 2000) and the concentration of nucleation mode particles and corresponding intermediate air ions is very low. The last circumstance allows neglecting the adsorption of the cluster ions by the nucleation mode particles and applying a simplified model of air ion attachment to the aerosol particles. Additionally, the effect of the atmospheric electric field in the air ion balance is neglected in the present study as well as it was neglected by Tammet and Kulmala (2005). This simplification is valid when considering the air ion balance inside of the forest, but it may be inadequate when applied to measurements in a strong electric field. The electric field creates near the ground surface the electrode effect, which is well known in atmospheric electricity (Israël, 1970; Willett, 1985). It results in a decrease in the concentration of air ions, which are forced away from the ground surface by the electric field, and in a slight increase in the concentration of the air ions of the opposite polarity. The ratio of positive and negative cluster ion concentrations is a good empiric indicator of the electrode effect. The atmospheric electric field undergoes strong variations and the electrode effect can easily be recognized in measurements when comparing the values of the positive and negative cluster ion concentrations in conditions of different field strength.

\section{Evolution of cluster ion concentrations}

The air ions are born in the acts of ionization described by the ionization rate $I$. The sink of cluster ions considers mutual recombination, adsorption by background aerosol particles, and adsorption by the canopy. The equations of evolution of positive and negative cluster ion concentrations $n^{+}$and $n^{-}$ are

$$
\left.\begin{array}{rl}
\frac{d n^{+}}{d t} & =I-\left(s_{c}^{+}+s_{p}^{+}+s_{f}^{+}\right) n^{+} \\
\frac{d n^{-}}{d t} & =I-\left(s_{c}^{-}+s_{p}^{-}+s_{f}^{-}\right) n^{-}
\end{array}\right\},
$$

where $s_{c}$ is the recombination sink of cluster ions on cluster ions of opposite polarity, $s_{p}$ is the sink of cluster ions on aerosol particles, and $s_{f}$ is the sink of cluster ions on forest canopy.

The recombination sinks are

$$
\left.\begin{array}{l}
s_{c}^{+}=\alpha n^{-} \\
s_{c}^{-}=\alpha n^{+}
\end{array}\right\},
$$

where $\alpha$ is the cluster ion recombination coefficient. Various authors refer to the value of the atmospheric cluster ion recombination coefficient in the range of 1.4$1.6 \times 10^{-12} \mathrm{~m}^{3} \mathrm{~s}^{-1}$ (Israël, 1970; Hoppel et al., 1986b).

In Eqs. (1) and (2) the properties of negative cluster ions are regarded as being different from the properties of positive 
cluster ions in a similar way as in the model by Dhanorkar and Kamra (2003).

\section{Aerosol sink of cluster ions}

The size distribution of aerosol particles is characterized by the total number concentration $N$ and the normalized distribution function $f(d)$ so that the concentration of particles in a size interval of the width of $d d$ around $d$ is $N f(d) d d$. The probability of a particle of the diameter of $d$ to carry $q$ elementary charges is denoted $p_{q}(d)$. The charge number $q$ is considered negative for the negative particles and positive for the positive particles. The coefficients of combination of positive and negative cluster ions with a particle of the size of $d$ and a charge number of $q$ are denoted by $\beta_{q}^{+}(d)$ and $\beta_{q}^{-}(d)$. If all these quantities are known, then the aerosol sinks of cluster ions can be calculated as

$$
\left.\begin{array}{l}
s_{p}^{+}=N \int_{d} \sum_{q} \beta_{q}^{+}(d) p_{q}(d) f(d) d d \\
s_{p}^{-}=N \int_{d} \sum_{q} \beta_{q}^{-}(d) p_{q}(d) f(d) d d
\end{array}\right\}
$$

The combination coefficients, often called the attachment coefficients, were estimated by different authors, e.g. Fuchs (1963), and Hoppel and Frick (1986b). Tammet and Kulmala (2005) included the effect of cluster ion size and particle diffusion, and proposed a computationally convenient mathematical approximation of combination coefficients, which results in the correct value of the ion-ion recombination coefficient in the limit of the cluster size. In the present study, the nucleation mode particles are not considered and the combination coefficients are calculated according to the simplified algorithm where the effect of particle diffusion is neglected

$$
\left.\begin{array}{c}
x=\frac{2 q d_{q}}{d+d_{\circ}} \\
\beta_{q}^{+}(d)=2 \pi D^{+}\left(d+d_{\circ}\right)\left(1-\frac{1}{1+0.3 q(q-1)+\left(d+d_{\circ}\right) / d_{H}}\right) \frac{x}{e^{x}-1} \\
\beta_{q}^{-}(d)=2 \pi D^{-}\left(d+d_{\circ}\right)\left(1-\frac{x}{1+0.3 q(q+1)+\left(d+d_{\circ}\right) / d_{H}}\right) \frac{x}{e^{x}-1}
\end{array}\right\} .
$$

$d_{q}$ is the characteristic length of the Coulomb attachment, $D^{ \pm}$is the diffusion coefficient of cluster ions of corresponding polarity, $d_{H}=15 \mathrm{~nm}$ is a coefficient of mathematical approximation, and $d_{o}=2\left(r_{\text {ion }}+d_{\text {extra }}\right)$ is the difference between the double collision distance and the particle diameter due to the size of the cluster ion and the Van der Waals forces. The characteristic length of the Coulomb attachment is

$d_{q}=\frac{e^{2}}{4 \pi \varepsilon_{\circ} k T} \approx \frac{273 \mathrm{~K}}{T} 61.2 \mathrm{~nm}$.

The average radius of the atmospheric cluster ions $r_{\text {ion }}$ is $0.35-0.4 \mathrm{~nm}$ and the extra distance due to the Van der Waals forces $d_{\text {extra }}$ was estimated $0.115 \mathrm{~nm}$ by Tammet (1995). The corresponding value of $d_{o}=1 \mathrm{~nm}$ is used in the present study.
The diffusion coefficient is related to the electric mobility $Z$ according to the Einstein equation

$D=\frac{k T}{e} Z$.

In case of large particles, an approximation by Tammet and Kulmala (2005) can be used

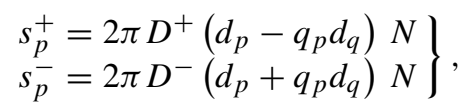

where $d_{p}$ and $q_{p}$, are the mean diameter and the algebraic mean charge number of aerosol particles. The size-charge distribution of aerosol particles is described with only three parameters in the model (7), which greatly simplifies the analysis of cluster ion measurements. The model is exact in the limit of large particles but the error in the size range of accumulation mode is considerable. The error can be evaluated and corrected comparing the approximation (7) with the exact model (3). The comparison was made for the steady state charge distribution of monodisperse particles controlled by the coefficient of unipolarity of cluster ion polar conductivities or ion asymmetry ratio (see Clement and Harrison, 1992)

$\gamma=\frac{n^{+} Z^{+}}{n^{-} Z^{-}}$

and presuming that the charge distribution of the particles changes only due to the cluster ion attachment:

$\frac{d p_{q}}{d t}=n^{+} \beta_{q-1}^{+} p_{q-1}+n^{-} \beta_{q+1}^{-} p_{q+1}-n^{+} \beta_{q}^{+} p_{q}-n^{-} \beta_{q}^{-} p_{q}$.

At first, the cluster ion sinks and particle mean charges were calculated according to Eq. (3) and then the approximate values of particle size and mean charge were restored solving Eq. (7) and additionally, the equations of an improved approximation:

$\left.\begin{array}{l}s_{p}^{+}=2 \pi D^{+}\left(\left(d_{p}-1.5 \mathrm{~nm}\right)-c q_{p} d_{q}\right) N \\ s_{p}^{-}=2 \pi D^{-}\left(\left(d_{p}-1.5 \mathrm{~nm}\right)+c q_{p} d_{q}\right) N\end{array}\right\}$,

where

$c=\frac{d_{p}+9 \mathrm{~nm}}{d_{p}+23 \mathrm{~nm}}$

is a size dependent correction coefficient.

The errors of the simplified parametric models are characterized by the relative deviations of restored values from the original values. The results of a numerical experiment are presented in Table 1.

Conclusion from the experiment is that the use of the approximation (7) for the accumulation mode particles is followed by relatively small errors of about a few percent in the estimated particle size, but considerable errors up to $30 \%$ in the estimated particle charge. The errors associated with the improved approximation do not exceed $5 \%$ in Table 1 . Thus the improved approximation (10) was used. 
Table 1. Test of approximations (7) and (10). $d_{p}$ and $q_{p}$ are the original values, $d *$ and $q *$ are the values restored according to approximate equations.

\begin{tabular}{ccccccc}
\hline \multirow{2}{*}{$d_{p}: \mathrm{nm}$} & $\gamma$ & $q_{p}$ & $\left(d *-d_{p}\right) / d_{p}$ & $\left(q *-q_{p}\right) / q_{p}$ & $\left(d *-d_{p}\right) / d_{p}$ & $\left(q *-q_{p}\right) / q_{p}$ \\
\hline \multirow{3}{*}{10} & 1.0 & 0.00 & $-18 \%$ & - & $-3.4 \%$ & - \\
& 1.5 & 0.05 & $-16 \%$ & $-43 \%$ & $-0.9 \%$ & $-0.5 \%$ \\
& 2.0 & 0.09 & $-11 \%$ & $-43 \%$ & $4.0 \%$ & $-1.6 \%$ \\
\hline \multirow{3}{*}{32} & 1.0 & 0.00 & $-4 \%$ & - & $0.3 \%$ & - \\
& 1.5 & 0.14 & $-3 \%$ & $-26 \%$ & $1.9 \%$ & $-0.9 \%$ \\
\hline \multirow{4}{*}{100} & 2.0 & 0.25 & $0 \%$ & $-26 \%$ & $4.8 \%$ & $-1.4 \%$ \\
& 1.0 & 0.00 & $-3 \%$ & - & $-1.3 \%$ & - \\
& 1.5 & 0.38 & $-1 \%$ & $-11 \%$ & $0.1 \%$ & $0.7 \%$ \\
& 2.0 & 0.66 & $1 \%$ & $-11 \%$ & $2.7 \%$ & $0.5 \%$ \\
& 1.0 & 0.00 & $-1 \%$ & - & $-0.6 \%$ & - \\
& 1.5 & 1.14 & $0 \%$ & $-4 \%$ & $0.8 \%$ & $0.4 \%$ \\
& 2.0 & 1.96 & $3 \%$ & $-4 \%$ & $3.5 \%$ & $0.4 \%$ \\
& 1.0 & 0.00 & $0 \%$ & - & $-0.2 \%$ & - \\
& 1.5 & 3.55 & $1 \%$ & $-1 \%$ & $1.2 \%$ & $0.2 \%$ \\
& 2.0 & 6.07 & $4 \%$ & $-1 \%$ & $3.9 \%$ & $0.2 \%$ \\
\hline
\end{tabular}

The aerosol sink is not exactly proportional to the particle size due to the nonlinear coefficient $c$ in Eq. (10). However, the deviation from the linearity is not large in the range of particle sizes dominating in the present measurements, and the approximation (10) is applied to the polydisperse atmospheric aerosols considering $d_{p}$ in Eq. (10) as the mean diameter of particles.

\section{Forest sink of cluster ions}

Deposition of cluster ions is a specific problem not considered in traditional models on dry deposition, reviewed by many authors, e.g. Seinfeld and Pandis (1998), Wesely and Hicks (2000). For gaseous species, reactivity is a major factor affecting the deposition velocity. In contrast to gases the cluster ions are fully adsorbed when reaching the surface of a conifer needle. The application of the models of dry deposition of particles in coniferous forest is described by Rannik et al. (2003a). In contrast to the particles, the cluster ion deposition can be described using the methods of the theory of heat transfer, reviewed e.g. by Incropera and Dewitt (2002). These methods allow developing a local model of cluster ion deposition onto individual needles.

Deposition of the ions and small particles onto the conifer needles was theoretically analyzed in a paper by Tammet et al. (2001) with an emphasis on the effect of the electric field on the tips of the top needles of the trees. The electric field is shielded and can be neglected inside the canopy. Above the canopy, the atmospheric electric field causes the asymmetry of the negative and positive ion concentrations, known in the atmospheric electricity as the electrode effect (Israël, 1970; Willett, 1985). In the present model, the effect of the electric field on the deposition of the air ions is neglected and only the Brownian component of the deposition is taken into account. Asymmetry of the ion concentrations is easy to identify in the measurements, which allows detecting possible errors due to this simplification.

Needles make most of the adsorbing surface of trees in boreal forests (Chen et al., 1997). For the sake of simplicity only the needles are considered in the present model and the deposition onto trunks and branches of the trees is ignored. In contrast to the aerosol particles the needles do not fly along with the moving air and the wind is an essential factor of the sink. The real orientation of conifer needles according to the wind is random. Deposition onto the needles, which are directed along the wind, is much less than deposition onto the transversal needles and can be neglected in the first approximation. In the first approximation, an inclined needle is considered as a composition of three Cartesian components, where one component is directed along the wind and two components are transversal to the wind. Thus $2 / 3$ of the needles are considered as cluster ion sinks in the present model and the orientation of these needles is assumed to be transversal to the wind.

A conifer needle is modeled as a segment of a thin and long cylinder. The heat flux and diffusion to a cylinder is described in terms of local deposition velocity $u_{\text {dep }}$ related to the longitudinal section of the cylinder: flux $=u_{\text {dep }} \times$ (area of the longitudinal section). All needles in a volume unit have the total longitudinal section area $L_{n} d_{n}$, where $L_{n}$ is the needle length density of the forest measured by the total length 
of needles in a volume unit, and $d_{n}$ is the average diameter of a needle. When $2 / 3$ of the needles are considered then the diffusion sink of cluster ions in the forest is

$s_{f}=\frac{2}{3} L_{n} d_{n} u_{\mathrm{dep}}$.

The local deposition velocity of air ions or nanometer particles from the transversal air flow related to the longitudinal section of a cylinder is expressed in terms of the Sherwood number (Incropera and Dewitt, 2002)

$u_{\text {dep }}=\frac{D}{d_{n}} S h$

and the forest sink of cluster ions is calculated in the present model as

$s_{f}=\frac{2}{3} L_{n} D S h$.

The amount of the adsorbing surfaces in a forest is usually characterized by the leaf area index. Different definitions of the index are used in the literature; see Chen et al. (1997). The most unambiguous concept is the total or all-sided leaf area index $\mathrm{LAI}_{\mathrm{t}}$, which is defined as the ratio of the total leaf or needle area in a vertical column of the forest to the crosssection area of the column. Thus $\mathrm{LAI}_{\mathrm{t}}=\pi d_{n} L_{n} h$, where $L_{n}$ is presented as the average value over the full height of the forest $h$, and the average needle length density of forest canopy can be estimated as

$L_{n}=\frac{\mathrm{LAI}_{\mathrm{t}}}{\pi d_{n} h}$.

The value of $L_{n}$ in a typical forest is of the same magnitude as the length of the chain of aerosol particles in a cubic meter $d_{p} N$. Thus the sink of cluster ions on the forest canopy is expected to be of the same magnitude as the sink of cluster ions on the aerosol particles.

The value of the Sherwood number for a thin cylinder can be estimated according to the Churchill-Bernstein heat transfer equation (see Incropera and Dewitt, 2002) translated into the terms of particle diffusion:

$S h=0.3+\frac{0.62 R e^{1 / 2} S c^{1 / 3}}{\left(1+(0.4 / S c)^{2 / 3}\right)^{1 / 4}}\left(1+\left(\frac{R e}{282000}\right)^{5 / 8}\right)^{4 / 5}$.

The Reynolds number $R e$ and the Schmidt number $S c$ are defined as

$R e=\frac{u d_{n}}{v}, \quad S c=\frac{v}{D}$,

where $u$ is the wind speed and $v$ is the kinematic viscosity of air. The dynamic viscosity of the air in SI units can be approximately calculated as $1.92 \times 10^{-7}(T: \mathrm{K})^{0.8}$, the density of air as $3.49 \times 10^{-3}(p: \mathrm{Pa}) /(T: \mathrm{K})$, and the kinematic viscosity as $\nu=5.5 \times 10^{-5}(T: \mathrm{K})^{1.8} /(p: \mathrm{Pa})$. The Sherwood number depends via the Schmidt number on the ion mobility and thus the deposition velocity is not exactly proportional to the mobility.

The Churchill-Bernstein equation is adequate when $R e \times S c>0.2$ and cannot be used in the still air. However, the allowed wind speed in the problem of deposition of cluster ions is as low as $0.007 \mathrm{~m} \mathrm{~s}^{-1}$. Complications will arise when the same model is applied in the calculation of the deposition of aerosol particles. The lowest wind speed for $10 \mathrm{~nm}$ particles is about $0.5 \mathrm{~m} \mathrm{~s}^{-1}$ and it increases inversely proportionally to the particle diffusion coefficient.

\section{Estimation of the ionization rate and the space charge}

In the steady state the derivatives in Eq. (1) equal to zero and the equations of evolution convert to the equations of the cluster ion balance

$$
\left.\begin{array}{l}
I-\alpha n^{+} n^{-}-\left(s_{p}^{+}+s_{f}^{+}\right) n^{+}=0 \\
I-\alpha n^{+} n^{-}-\left(s_{p}^{-}+s_{f}^{-}\right) n^{-}=0
\end{array}\right\}
$$

All quantities in Eq. (18) are determined by variables $I, n^{+}$, $n^{-}, T, Z^{+}, Z^{-}, d_{p}, q_{p}, N, L_{n}, u, d_{n}, p$, and constants $\alpha, k$, $\varepsilon_{o}, e$. The variables $u$ and $d_{n}$ are presented only as the product $u d_{n}$ which is considered as a compound variable. If the values of ten variables $n^{+}, n^{-}, T, Z^{+}, Z^{-}, d_{p}, N, L_{n}, u d_{n}$, and $p$ are measured, then Eq. (18) consist of two unknowns $I$ and $q_{p}$, and can be easily solved.

Equation (18) is valid when all sources and sinks are steady in time and uniform in space. The time restriction is limited by the lifetime of cluster ions, which is short enough to accept the steady state when interpreting the measurements in the present study. The space restriction creates problems, because the air is flowing in the forest between the trees and the forest sink of ions, as well as the activity of alpha-active substances, deposited on vegetation, are essentially inconsistent in space. If Eq. (18) is applied in the conditions of heterogeneous sources and sinks, then the results should be interpreted as certain average values over the windward zone of ion origin considering the decay of cluster ions with the time scale of about $100 \mathrm{~s}$.

For the sake of the mathematical convenience a new parameter is defined, the equivalent concentration of cluster ion absorption in the forest:

$N_{f}=\frac{L_{n}}{3 \pi d_{q}} S h$.

The equivalent concentration $N_{f}$ weakly depends on the mobility via the Schmidt number. Thus it has different values for positive and negative air ions. The sink of air ions on the forest canopy is written now in the similar style as the aerosol sink

$s_{f}^{ \pm}=2 \pi D^{ \pm} d_{q} N_{f}^{ \pm}$ 


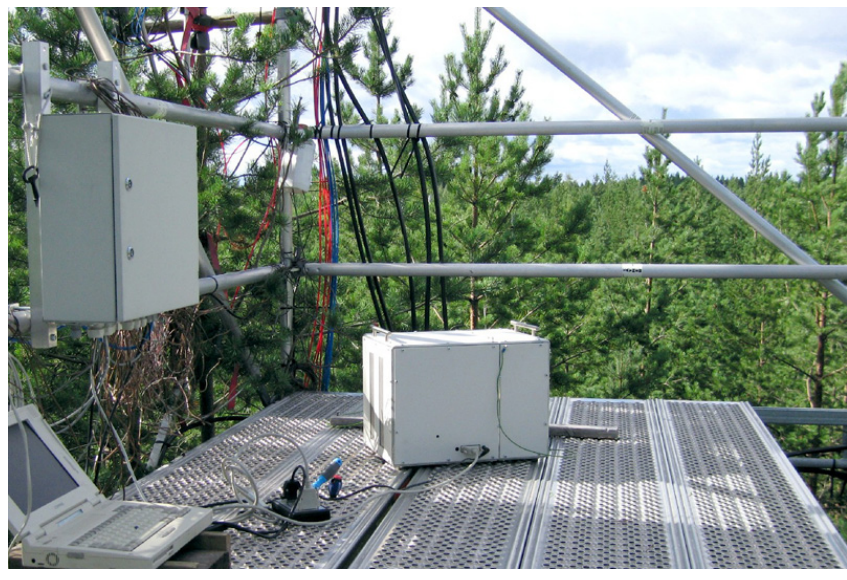

Fig. 1. BSMA2 (in the center of the picture) between pine tops.

despite the fact that it is not exactly proportional to the diffusion coefficient of air ions. The steady state equations of the cluster ion concentration in the new terms are

$$
\left.\begin{array}{l}
I-\alpha n^{+} n^{-}=2 \pi D^{+} n^{+}\left(\left(d_{p}-1.5 \mathrm{~nm}\right) N-c q_{p} d_{q} N+d_{q} N_{f}^{+}\right) \\
I-\alpha n^{+} n^{-}=2 \pi D^{-} n^{-}\left(\left(d_{p}-1.5 \mathrm{~nm}\right) N+c q_{p} d_{q} N+d_{q} N_{f}^{-}\right)
\end{array}\right\} .
$$

The diffusion coefficients are proportional to the electric mobilities and this allows writing the equation for $q_{p}$ as

$$
\begin{gathered}
\left(\left(d_{p}-1.5 \mathrm{~nm}\right) N-c q_{p} d_{q} N+d_{q} N_{f}^{+}\right) \gamma= \\
\left(d_{p}-1.5 \mathrm{~nm}\right) N+c q_{p} d_{q} N+d_{q} N_{f}^{-} .
\end{gathered}
$$

The solution is

$q_{p}=\frac{(\gamma-1)\left(d_{p}-1.5 \mathrm{~nm}\right)}{(\gamma+1) c d_{q}}+\frac{\gamma N_{f}^{+}-N_{f}^{-}}{c(\gamma+1) N}$.

Next the ionization rate can be calculated from any of Eqs. (21).

The particle-carried component of the space charge is $q_{p} N$ and the total space charge density of the air is

$\rho=\left(q_{p} N+n^{+}-n^{-}\right) e$.

The space charge density is a well-known quantity in atmospheric electricity (see Israël, 1973) and can be directly measured. This gives an additional possibility to associate the model with measurements, unfortunately not used in the present study due to the lack of required equipment.

\section{The measurement of cluster ions}

Measurements were performed at the Hyytiälä forest research station $\left(61^{\circ} 51^{\prime} \mathrm{N}, 24^{\circ} 17^{\prime} \mathrm{E}, 180 \mathrm{~m}\right.$ a.s.l. $)$ of the University of Helsinki, Finland. The layer of soil over the partially uncovered igneous bedrock is thin in Hyytiälä and the radioactivity of the ground and the air may be significant. This results in cluster ion concentrations of $500-800 \mathrm{~cm}^{-3}$ (Hirsikko et al., 2005), about twice the expected concentrations at a typical rural site (Hõrrak et al., 2003).

The air ion measurements were carried out by means of two Balanced Scanning air ion Mobility Analyzers BSMA1 and BSMA2. The instruments have been described by Tammet $(2004,2006)$. A large air flow of about $0.05 \mathrm{~m}^{3} \mathrm{~s}^{-1}$ is used in BSMA to avoid sampling errors and drying of nanometer particles. A standard measurement cycle lasts for $10 \mathrm{~min}$ and results in mobility and size distributions of air ions of both polarities in the size range from molecular ions to $7 \mathrm{~nm}$ charged particles. The charged nanometer particles can be reliably detected only during the nucleation events. In the present study, only the cluster ion number concentrations and average electric mobilities were recorded.

BSMA is an instrument of absolute calibration, where the cluster ion concentrations and mobilities are calculated according to the values of geometric dimensions, voltages, and air flow rates. The measurements of these parameters contain some uncertainties, which result in small divergences between the calibrations of the two initially independently calibrated instruments. Thus the two instruments were compared in a preparative experiment when both BSMAs were working close to each other during $6 \mathrm{~h}$. The detected difference in the initial calibrations was less than $4 \%$ and it was considered by introducing the correction coefficients equalizing the results of the comparison experiment. Including the correction replaces the initial calibration by the average calibration and suppresses systematic errors in the differences between measurements made with the two instruments. The uncertainty of measurements of the cluster ion concentration and mean mobility due to the instrumental systematic errors is estimated to be about $5 \%$ in the initial calibration procedures and, after the application of the equalizing correction, the divergence between the systematic errors of two instruments is expected to be less than this value.

In a second preparative experiment the cluster ion concentrations were measured simultaneously with two instruments located at the same height but separated with a horizontal distance of about $150 \mathrm{~m}$. A difference of $5 \%$ of the average ion concentrations was detected. The difference can be explained by local inhomogeneities of the ground radioactivity.

The main experiment was performed from 17:30, $17 \mathrm{Au}-$ gust, until 10:00, 18 August, lasting $16.5 \mathrm{~h}$. The local zone time UT +2 is used everywhere in the present paper. There were no nucleation events, which could make the abovedescribed theoretical model inadequate. BSMA1 was located in a small wooden cottage and the air intake was about $2 \mathrm{~m}$ from the ground. BSMA2 was about $50 \mathrm{~m}$ away on the upper level of a metal tower between the tops of the pines (Fig. 1); the air intake was about $14 \mathrm{~m}$ above the ground. A uniform Pinus sylvestris stand of about 2300 stems per hectare, which was established in 1962, surrounds the measurement site. The average diameter of needles $d_{n}$ is estimated to be $0.9 \mathrm{~mm}$ 


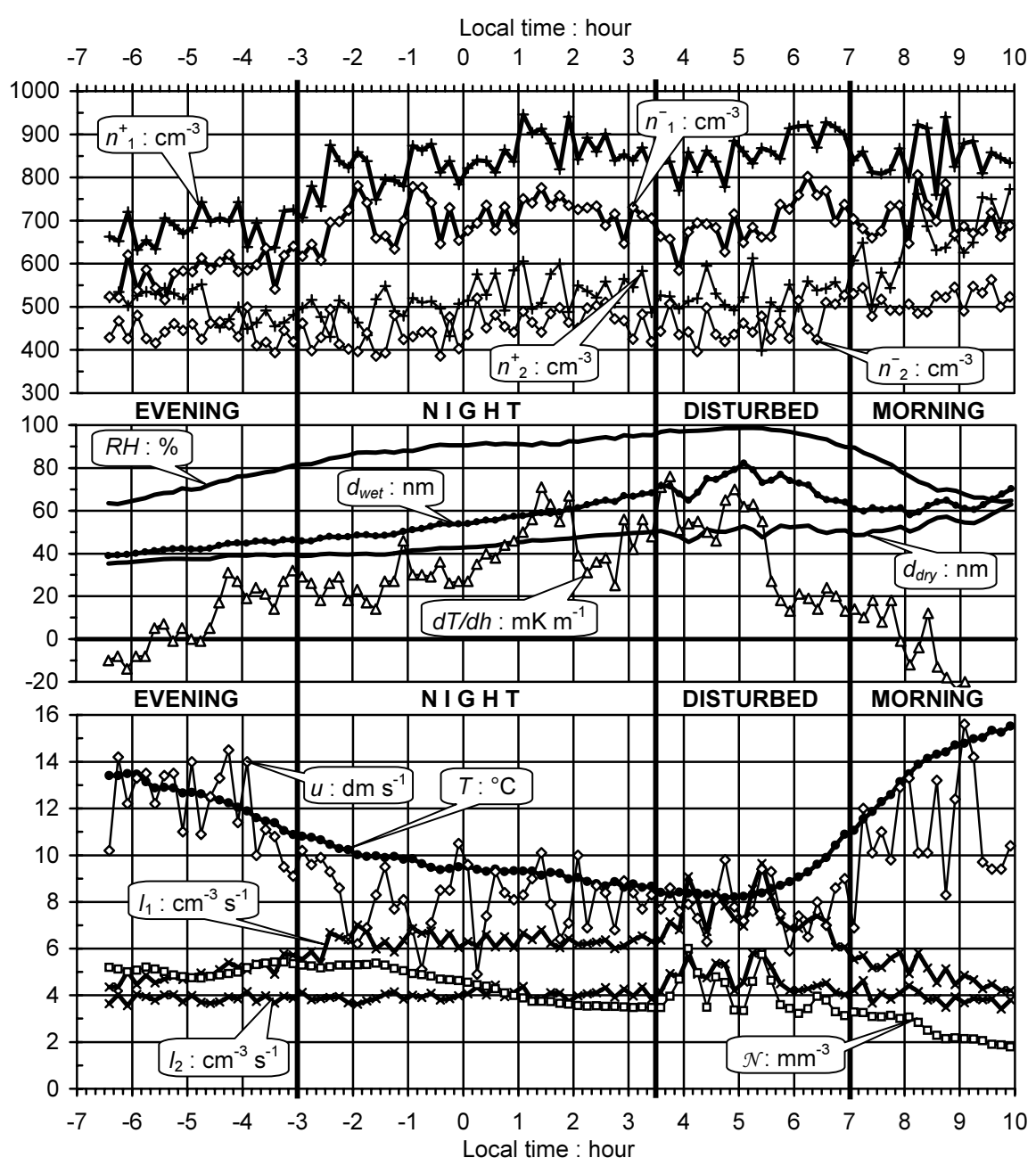

Fig. 2. Time variation of the measured and calculated variables. Zero time corresponds to the midnight between 17 and 18 Augus 2005 . Index 1 denotes the records of BSMA1 ( $2 \mathrm{~m}$ above the ground) and index 2 the records of BSMA2 (14 m above the ground). Four time intervals are delimited with bold vertical lines.

according to handbooks of forestry. The average height of trees was $14 \mathrm{~m}$ and the total needle area index $\mathrm{LAI}_{T}$ was 7 about 3 years before the present measurement (Rannik et al., 2003b). These parameters correspond to the average needle length density of about $180 \mathrm{~m}^{-2}$.

The vertical needle distribution in the Hyytiälä forest was described by Rannik et al. (2003b). The distribution density exceeds the full height average between 7 and $13 \mathrm{~m}$ with the maximum at the height of about $11 \mathrm{~m}$. The lifetime of cluster ions is about two minutes and the windward zone from which the ions reach the instrument extends up to hundreds of meters. In case of BSMA1 located at the height of $2 \mathrm{~m}$ the zone of ion origin is located mainly in the region of the low density of needles, but it additionally contains the undergrowth of the forest. BSMA2, located at the height of $14 \mathrm{~m}$, is sampling the air from the space above the forest canopy, as well as from the region of high density of needles. Unfortunately, a correct estimation of the average needle density over the zone of ion origin on the basis of the available data is impossible. Thus the calculations below are performed using a rough estimate of the value of the needle density of $100 \mathrm{~m}^{-2}$ for both sampling sites.

\section{The data}

The cluster ion concentrations and mobilities are presented as average values over $10 \mathrm{~min}$ time intervals. The air ion measurements are accompanied by the meteorological and aerosol data provided by P. P. Aalto from the SMEAR II datasets. In the present study the values of the following meteorological parameters are used:

- $T$ - air temperature measured in the SMEAR mast at the height of $4.2 \mathrm{~m}$; 
Table 2. Statistical estimates of mean values and standard deviations of measurements during four time intervals and the whole measurement period, written as average \pm st-deviation. The index 1 denotes the lower and the index 2 the upper location of the instrument.

\begin{tabular}{lccccc}
\hline Parameter & Evening & Night & Disturbed & Morning & Whole period \\
\hline Hour & $-6.5 \ldots-3.0$ & $-3.0 \ldots 3.5$ & $3.5 \ldots 7.0$ & $7.0 \ldots 10$ & $-6.5 \ldots 10$ \\
$T:{ }^{\circ} \mathrm{C}$ & $12.4 \pm 0.8$ & $9.5 \pm 0.6$ & $8.8 \pm 0.8$ & $13.8 \pm 1.4$ & $10.8 \pm 2.1$ \\
$\mathrm{dT} / \mathrm{dh}: \mathrm{mK} \mathrm{m}^{-1}$ & $9 \pm 15$ & $37 \pm 14$ & $42 \pm 22$ & $-7 \pm 17$ & $24 \pm 25$ \\
$u: \mathrm{m} \mathrm{s}^{-1}$ & $1.21 \pm 0.17$ & $0.81 \pm 0.14$ & $0.78 \pm 0.10$ & $1.10 \pm 0.22$ & $0.95 \pm 0.24$ \\
$\mathrm{RH}: \%$ & $71.6 \pm 5.7$ & $89.9 \pm 3.6$ & $96.5 \pm 2.5$ & $73.8 \pm 8.4$ & $84.5 \pm 11.2$ \\
$n_{1}^{+}: \mathrm{cm}^{-3}$ & $683 \pm 37$ & $840 \pm 52$ & $862 \pm 45$ & $849 \pm 47$ & $813 \pm 82$ \\
$n_{2}^{+}: \mathrm{cm}^{-3}$ & $501 \pm 35$ & $519 \pm 44$ & $524 \pm 43$ & $655 \pm 75$ & $541 \pm 73$ \\
$n_{1}^{-}: \mathrm{cm}^{-3}$ & $582 \pm 38$ & $707 \pm 46$ & $697 \pm 52$ & $702 \pm 43$ & $678 \pm 67$ \\
$n_{2}^{-}: \mathrm{cm}^{-3}$ & $442 \pm 26$ & $450 \pm 37$ & $459 \pm 38$ & $516 \pm 25$ & $462 \pm 42$ \\
$Z_{1}^{+}: \mathrm{cm}^{2} \mathrm{~V}^{-1} \mathrm{~s}{ }^{-1}$ & $1.51 \pm 0.02$ & $1.49 \pm 0.02$ & $1.50 \pm 0.03$ & $1.43 \pm 0.04$ & $1.48 \pm 0.04$ \\
$Z_{2}^{+}: \mathrm{cm}^{2} \mathrm{~V}^{-1} \mathrm{~s}^{-1}$ & $1.57 \pm 0.02$ & $1.56 \pm 0.03$ & $1.57 \pm 0.04$ & $1.49 \pm 0.05$ & $1.55 \pm 0.04$ \\
$Z_{1}^{-}: \mathrm{cm}^{2} \mathrm{~V}^{-1} \mathrm{~s}-1$ & $1.60 \pm 0.03$ & $1.59 \pm 0.03$ & $1.65 \pm 0.04$ & $1.57 \pm 0.04$ & $1.60 \pm 0.04$ \\
$Z_{2}^{-}: \mathrm{cm}^{2} \mathrm{~V}^{-1} \mathrm{~s}^{-1}$ & $1.56 \pm 0.02$ & $1.57 \pm 0.03$ & $1.62 \pm 0.04$ & $1.58 \pm 0.02$ & $1.58 \pm 0.04$ \\
$N: \mathrm{cm}^{-3}$ & $5070 \pm 226$ & $4389 \pm 721$ & $4063 \pm 839$ & $2540 \pm 535$ & $4128 \pm 1043$ \\
$\mathrm{dry} d_{p}: \mathrm{nm}$ & $37.9 \pm 1.4$ & $43.9 \pm 3.7$ & $50.4 \pm 2.0$ & $54.2 \pm 4.1$ & $45.9 \pm 6.5$ \\
wet $d_{p}: \mathrm{nm}$ & $42.9 \pm 2.4$ & $55.6 \pm 6.7$ & $72.2 \pm 5.2$ & $62.4 \pm 3.1$ & $57.6 \pm 11.1$ \\
\hline
\end{tabular}

- $d T / d h$ - temperature gradient calculated according to the temperature measurements at the heights of 4.2 and $16.8 \mathrm{~m}$;

- $u$ - wind speed measured at the height of $8.4 \mathrm{~m}$;

- $R H$ - relative humidity calculated according to the measured concentration of water vapor and temperature at the height of $4.2 \mathrm{~m}$.

The measurements of wind speed were available for the heights of 8.4 and $16.8 \mathrm{~m}$. The ratio of average wind speeds in these heights during 18 August 2005, was about 2.4. The wind speeds in the zones of ion origin are estimated $0.7 u$ for BSMA1 and $1.2 u$ for BSMA2. The precision of these estimates is not critical, because the coefficient of transfer of relative error to the estimate of the ionization rate is about 0.1 , as is explained in the following section of the paper.

The original aerosol data contain the size distributions and total number concentrations of particles measured at the height of about $2 \mathrm{~m}$ above the ground with a time resolution of $10 \mathrm{~min}$ by the Differential Mobility Particle Sizer DMPS described briefly by Laakso et al. (2004b). The concentration of nucleation mode particles during the measurements was low and their role in the aerosol sink of cluster ions is negligible. The residence time of air in a forest is measured in minutes. The lifetime of particles in the accumulation mode is measured in days. Thus it is reasonable to assume that they are homogeneously distributed in the forest. The difference in the particle concentration at heights of $2 \mathrm{~m}$ and $14 \mathrm{~m}$ is expected to be below the measurement uncertainty.

The DMPS measures dry particle size distribution in the size range of 3-1000 nm. The diameters of hygroscopic par- ticles in the natural humid air are bigger than those recorded by DMPS. The humid growth rate was estimated according to the parameterization by Zhou (2001) adapted to the Hyytiälä conditions by Laakso et al. (2004b):

$\frac{d_{\text {wet }}}{d_{\text {dry }}}=\left(1-\frac{R H}{100}\right)^{-\frac{d_{\text {dry }}}{3215 \mathrm{~nm}}-0.0847}$.

Equation (25) is not valid for particles of size above a few hundred nanometers. During the present measurements, the cluster ion sink was distributed in a relatively narrow size interval and the average size of particles was always in the range of validity of (25). Thus the transformation from dry to wet diameters was applied not to the full distribution but to the average diameter.

A small fraction of the cluster ion sink is caused by particles with sizes larger than $1000 \mathrm{~nm}$, which are not recorded by the DMPS. Laakso et al. (2004b) showed that the extra sink created by the large particles in a similar situation was about $2 \%$ of the sink created by the particles of size up to $1000 \mathrm{~nm}$. The concentration of the coarse mode particles was measured using an Aerodynamic Particle Sizer APS during a part of the time of the present measurements and the relative concentration of the coarse mode appeared in all measurements less than during the measurements by Laakso et al. (2004b). Thus the sink of cluster ions on aerosol particles during the present measurements is calculated considering the DMPS records and multiplied by a correction factor 1.02 during the data processing. This correction is less than the uncertainty of aerosol measurements.

The time variation of measured and calculated quantities and the partition of the measurement period are shown in 
Fig. 2. The calculated quantities $I_{1}$ and $I_{2}$ are explained in the following sections of the paper. The whole measurement period is apportioned to four time intervals so that the meteorological conditions inside of every interval are more or less uniform. The main criterions of the splitting are the wind speed and the temperature gradient, which affect the air exchange in the forest and thus the air ion concentrations. The intervals are called "evening", "night", "disturbed", and "morning". The time variations of the measured and calculated quantities are regular with the exception of the interval "disturbed" when the smoothness of the time series of the aerosol particle concentration $N$ is broken and the curve has several high peaks. These peaks have no reflection in the cluster ion concentration measurements and it is not excluded that the peaks are caused by instrumental problems. The peculiarity of this period is very high relative humidity. The measurements in this time interval are qualified as problematic in the present study because the origin of the peaks of aerosol concentration remained unidentified. The results during the "disturbed" time interval were left out of the discussion about the aerosol sink and ionization rate.

The visible fluctuations of cluster ion concentrations in the diagram are partially caused by the instrument noise, but in bigger amount by the natural variations. The natural variations are induced mostly by the fluctuations in the wind and air mixing in the conditions of steep vertical gradients of cluster ion concentration.

The average values and standard deviations of meteorological parameters, cluster ion concentrations and mobilities, and aerosol parameters in the two heights are shown in Table 2.

The ratio of the whole period average concentrations of positive and negative cluster ions $n^{+} / n^{-}$was 1.17 at the height of $2 \mathrm{~m}$, where the atmospheric electric field is shielded and the electrode effect is negligible. The value of this ratio at the height of $14 \mathrm{~m}$ was 1.20 . Thus the influence of the electrode effect on the cluster ion concentrations at the height of $14 \mathrm{~m}$ was small and is neglected in the present study.

\section{Transfer of measurement errors to the estimates of the ionization rate and the particle charge}

The measurement errors affect the solutions of Eq. (21) to a different extent. All arguments and the ionization rate can be characterized by relative uncertainties. Thus the error transfer from an argument $x_{i}$ to the estimate of the ionization rate can be described with the dimensionless ratio of the relative deviations

$K_{i}(I)=\frac{x_{i}}{I} \frac{\partial I}{\partial x_{i}}$,

which is interpreted as the factor of error amplification.

Unlike the ionization rate, the particle mean charge $q_{p}$ can have positive or negative values, and its measurements cannot be characterized by a relative uncertainty. In this case the
Table 3. The error transfer characteristics in case of full period averages for measurements at the heights of $2 \mathrm{~m}$ and $14 \mathrm{~m}$.

\begin{tabular}{lcccc}
\hline \multirow{2}{*}{ Argument } & \multicolumn{2}{c}{$K(I)$} & \multicolumn{2}{c}{$\Delta q_{p}$} \\
& $h=2 \mathrm{~m}$ & $h=14 \mathrm{~m}$ & $h=2 \mathrm{~m}$ & $h=14 \mathrm{~m}$ \\
\hline$n^{+}$ & 0.54 & 0.51 & 0.74 & 0.78 \\
$n^{-}$ & 0.59 & 0.58 & -0.74 & -0.78 \\
$\sqrt{n^{+} n^{-}}$ & 1.13 & 1.09 & 0.00 & 0.00 \\
$n^{+} / n^{-}$ & -0.02 & -0.03 & 0.74 & 0.78 \\
$Z^{+}$ & 0.38 & 0.38 & 0.68 & 0.70 \\
$Z^{-}$ & 0.42 & 0.44 & -0.68 & -0.71 \\
$N$ & 0.68 & 0.67 & -0.02 & -0.03 \\
$d_{p}$ & 0.69 & 0.69 & 0.01 & 0.02 \\
$L_{n}$ & 0.19 & 0.24 & 0.02 & 0.03 \\
$u d_{n}$ & 0.09 & 0.12 & 0.01 & 0.02 \\
$T$ & 0.76 & 0.77 & 0.07 & 0.09 \\
$p$ & 0.02 & 0.03 & 0.00 & 0.00 \\
$\alpha$ & 0.13 & 0.09 & 0.00 & 0.00 \\
\hline
\end{tabular}

uncertainty transfer is described by the absolute deviation of the estimated value when an argument is changed from zero to its actual value

$\Delta_{i} q_{p}=\frac{\partial q_{p}}{\partial x_{i}} x_{i}$

The characteristics of error transfer depend on the values of the parameters. The error transfer in a specific problem can be characterized calculating the attributes (26) and (27) on the occasion of average values of the arguments. The results for average values for the full period of the present measurements in Hyytiälä are shown in Table 3. The cluster ion recombination coefficient $\alpha$ is treated as a parameter here because its value is known with the uncertainty of about $5 \%$. The information about cluster ion concentration is included in two ways: by the indirect values of concentrations and by the geometric average and the ratio. The second way allows to estimate the effect of correlated errors in the concentrations for two polarities.

\section{Discussion}

The average values of cluster ion concentrations presented in Table 2 and time variations shown in Fig. 2 are consistent with the general knowledge about cluster ion sources and sinks. The concentration of aerosol particles in Hyytiälä is low (average value of about $4000 \mathrm{~cm}^{-3}$ during the present experiment) and thus the absolute levels of the cluster ion concentrations are high when compared with the typical rural locations in lower latitudes. E.g. the average cluster ion concentrations $n^{+}=274 \mathrm{~cm}^{-3}$ and $n^{-}=245 \mathrm{~cm}^{-3}$ in Tahkuse $\left(58^{\circ} 31^{\prime} \mathrm{N} 24^{\circ} 56^{\prime} \mathrm{E}\right)$ at the height of $5 \mathrm{~m}$ from the ground during the 14-month period in 1993-1994 (Hõrrak et al., 


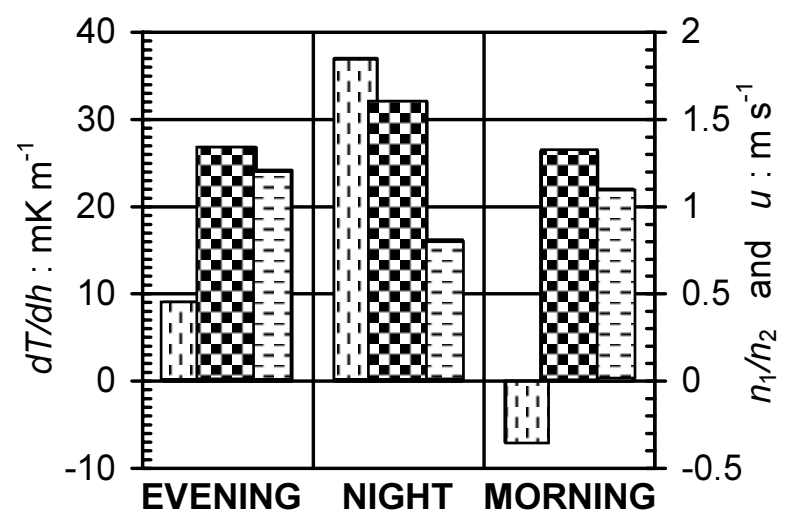

Fig. 3. Average values of the temperature gradient (left columns), the ratio of cluster ion concentrations $\left(n_{1}^{+}+n_{1}^{-}\right) /\left(n_{2}^{+}+n_{2}^{-}\right)$(mid columns), and the wind speed at $8.4 \mathrm{~m}$ (right columns) during three time intervals.

2000) were less than half of the monthly mean values 600 $900 \mathrm{~cm}^{-3}$ in Hyytiälä at the height of $2 \mathrm{~m}$ from the ground recorded during the 12-month period in 2003-2004 (Hirsikko et al., 2005).

The average cluster ion concentrations shown in Table 2 between the tops of pines at $14 \mathrm{~m}$ from the ground $\left(n_{2}^{+}=541 \mathrm{~cm}^{-3}\right.$ and $\left.n_{2}^{-}=462 \mathrm{~cm}^{-3}\right)$ were about 1.5 times less than at $2 \mathrm{~m}$ from the ground $\left(n_{1}^{+}=813 \mathrm{~cm}^{-3}\right.$ and $\left.n_{1}^{-}=678 \mathrm{~cm}^{-3}\right)$. A probable reason for the higher concentration at the lower level is the increased ionization rate near the ground. The ratio of concentrations at the lower and upper levels increases with the decrease in the vertical mixing of the air, which depends on the wind speed and the temperature gradient. The correlation of the air vertical mixing factors and the ratio of average ion concentrations are illustrated in Fig. 3.

The fluctuations in the measurements of ion concentrations do not cause problems when estimating the ionization rate according to Eq. (21) because the solution of the equations does not amplify the measurement errors, as shown in Table 3. The measurement errors of some other arguments like air pressure, recombination coefficient and wind speed are effectively suppressed, e.g. a 3\% error in the value of atmospheric pressure results in about $0.1 \%$ error in the ionization rate, because the error transfer coefficient is $1 / 30$. However, the transfer of fluctuations of the cluster ion measurements to the estimates of particle mean charge appears to be unfavorably large: a typical fluctuation of $10 \%$ in the cluster ion concentration measurements brings along the fluctuation about 0.064 in the particle mean charge, which is equivalent to $270 \mathrm{e} \mathrm{cm}^{-3}$ in the space charge carried by aerosol particles. This fluctuation is of the same magnitude as the typical values of the parameter itself.
Ionization rate and particle mean charge were calculated solving Eq. (21) expecting $\alpha=1.5 \times 10^{-12} \mathrm{~m}^{3} \mathrm{~s}^{-1}$. The time variation of the calculated ionization rate during the experiment is shown in Fig. 2. Space charge is not depicted in the diagrams because of large fluctuations. The fluctuations are strongly suppressed in the averages over the time intervals, which are presented in Table 4.

The values of the ionization rate presented in Table 4 and depicted in Fig. 2 are a little lower than the average value of $6.6 \mathrm{~cm}^{-3} \mathrm{~s}^{-1}$ found by Tuomi (1989) in a suburb of Helsinki, and a little higher than the value of $4.5 \mathrm{~cm}^{-3} \mathrm{~s}^{-1}$ found by Laakso et al. (2004b) in Hyytiälä according to the measurements of ionizing radiations, but essentially higher than the value of $2.6 \mathrm{~cm}^{-3} \mathrm{~s}^{-1}$ calculated according to the air ion measurements. The factors of this low value are assumed to be:

- the measurements were made in different meteorological and aerosol conditions;

- the mobility of cluster ions was underestimated;

- the dry deposition of cluster ions on forest canopy was neglected.

The effect of the last two factors is characterized by test calculations presented in Table 5. The mean mobility of $1.55 \mathrm{~cm}^{2} \mathrm{~V}^{-1} \mathrm{~s}^{-1}$ measured in the present study is 1.26 times more than $Z=1.23 \mathrm{~cm}^{2} \mathrm{~V}^{-1} \mathrm{~s}^{-1}$ expected by Laakso et al. Readjusting the mobility from 1.23 to $1.55 \mathrm{~cm}^{2} \mathrm{~V}^{-1} \mathrm{~s}^{-1}$ results in an increase of the estimated ionization rate by a factor of about 1.2 (Table 5). The effect of taking into account the forest sink seems to be more essential, because the ratio of corresponding estimates in Table 5 is a little higher.

A special result of the present measurement is the discovery of an essential difference in the ionization rates at the two heights as shown in Table 4 and Fig. 2. The difference is increased during the night when the air exchange in the forest is suppressed. The general knowledge about the factors of ionizing rate according to Israël $(1970,1973)$ and Hoppel et al. (1986a) is:

- Cosmic rays produce $I \approx 2 \mathrm{~cm}^{-3} \mathrm{~s}^{-1}$ without any considerable height variation in the lowest kilometer of atmosphere.

- Gamma rays emitted from the ground produce typically about the same amount of ions, the ionization rate varies strongly with the location, reaches the height of about $200 \mathrm{~m}$ and is nearly uniform in the lowest $10-20 \mathrm{~m}$.

- Beta radiation emitted from the ground is weak and produces only negligible amount of ions in the lowest few meters.

- Alpha radiation of radon ${ }^{222} \mathrm{Rn}$ and its progeny is the third main ionizing agent after cosmic and gamma rays. Radon and its progeny are distributed nearly uniformly in the lowest hundred meters over the open landscape 
Table 4. Statistical estimates of mean values and standard deviations of the ionization rate, particle carried space charge and full space charge density during the undisturbed time intervals written as average \pm st-deviation. The last column corresponds to the whole measurement period where the disturbed interval is skipped.

\begin{tabular}{lccccc}
\hline Parameter & Height & Evening & Night & Morning & Undisturbed \\
\hline$I: \mathrm{cm}^{-3} \mathrm{~s}^{-1}$ & $2 \mathrm{~m}$ & $4.96 \pm 0.40$ & $6.31 \pm 0.35$ & $4.98 \pm 0.56$ & $5.64 \pm 0.79$ \\
& $14 \mathrm{~m}$ & $3.85 \pm 0.17$ & $4.00 \pm 0.20$ & $3.92 \pm 0.31$ & $3.94 \pm 0.23$ \\
$q_{p}$ & $2 \mathrm{~m}$ & $0.063 \pm 0.037$ & $0.076 \pm 0.034$ & $0.093 \pm 0.044$ & $0.077 \pm 0.038$ \\
& $14 \mathrm{~m}$ & $0.083 \pm 0.051$ & $0.098 \pm 0.068$ & $0.184 \pm 0.093$ & $0.114 \pm 0.080$ \\
$\rho: \mathrm{e} \mathrm{cm}^{-3}$ & $2 \mathrm{~m}$ & $424 \pm 226$ & $464 \pm 168$ & $387 \pm 152$ & $436 \pm 183$ \\
& $14 \mathrm{~m}$ & $488 \pm 304$ & $504 \pm 369$ & $594 \pm 282$ & $520 \pm 332$ \\
\hline
\end{tabular}

in conditions of normal turbulent exchange but can be accumulated in the lowest meters during inversions.

- Alpha radiation of thoron ${ }^{220} \mathrm{Rn}$ is present only below the height of a couple of meters. The role of thoron in generating atmospheric ions is poorly understood.

- Activity of actinon ${ }^{219} \mathrm{Rn}$ in the natural air is negligible.

During the nocturnal calms the accumulated radon and thoron can cause ionization rates up to $100 \mathrm{~cm}^{-3} \mathrm{~s}^{-1}$ and even more below one meter (Crozier and Biles, 1966; Dhanorkar and Kamra, 1994; Nagaraja et al., 2003). Additionally, the deposited radon daughters can create air ions close to the ground surface. Willett (1985) modeled the atmospheric electric electrode effect over the grass-covered ground and pointed out that the alpha radiation of the deposited radon daughters is an important ionizing factor despite the fact that the path of alpha rays is only few centimeters. The situation inside the forest is specific and the alpha radiation of the radon daughters deposited onto needles of trees should additionally be considered. The radon progeny is carried by aerosol particles and positive cluster ions, and can be deposited onto the needles due the Brownian diffusion in the similar way as the ordinary cluster ions. When the lifetime of the radioactive substances exceeds the air residence time in the forest canopy, then needles can collect radioactivity even more than created by the radon decay inside the forest.

Possible factors that explain the higher ionization rate at the height of $2 \mathrm{~m}$ when compared with the height of $14 \mathrm{~m}$ are assumed to be:

- accumulation of radon and radon progeny in the lowest few meters during the nighttime low air exchange period;

- ionization of the air by the radioactive substances collected onto the surfaces of conifer needles and the forest undergrowth;

- presence of thoron ${ }^{220} \mathrm{Rn}$ in the first meters from the ground;
Table 5. Comparison of estimates of the ionization rate for the undisturbed time intervals considering and neglecting the dry deposition of cluster ions on the forest canopy.

\begin{tabular}{|c|c|c|c|}
\hline Forest & Mobility & \multicolumn{2}{|c|}{ Estimate of $I: \mathrm{cm}^{-3} \mathrm{~s}^{-1}$} \\
\hline considered & as measured & 5.64 & 3.94 \\
\hline neglected & as measured & 4.48 & 2.90 \\
\hline considered & $1.23 \mathrm{~cm}^{2} \mathrm{~V}^{-1} \mathrm{~s}^{-1}$ & 4.75 & 3.26 \\
\hline neglected & $1.23 \mathrm{~cm}^{2} \mathrm{~V}^{-1} \mathrm{~s}^{-1}$ & 3.75 & 2.36 \\
\hline
\end{tabular}

- beta radiation emitted from the ground.

The first factor is a commonly accepted reason for the decrease in the ionization rate with height. The second factor may contribute more at the height of $2 \mathrm{~m}$, because the air sampled at the height of $14 \mathrm{~m}$ is essentially sojourned above the forest during the lifetime of cluster ions and this part of the air is not exposed to the alpha rays emitted by the surfaces of the forest canopy. The activity of thoron and its progeny in the Hyytiälä air was insignificant in measurements by Laakso et al. (2004b) when compared with the activity of ${ }^{222} \mathrm{Rn}$ and its progeny. The level of ground-emitted beta radiation in Hyytiälä is unknown. In typical situations this factor is evaluated as negligible (Israël, 1970, 1973). Unfortunately we have no information, which could allow estimating the quantitative role of the different factors in the present measurements.

The alpha radiation of the surfaces of conifer needles is a factor not considered in the earlier research. This factor was also neglected when the ionization rate in Hyytiälä was calculated according to the ionizing radiations (Laakso et al., $2004 \mathrm{~b}$ ). If the alpha radiation of the needles proves to be essential, then the corresponding values of the ionization rate may be underestimated. Additional measurements and theoretical research are required to detect the alpha activity of the surfaces of the forest canopy and test the hypothesis. 
Table 6. Cluster ion average sinks $\left(\mathrm{ks}^{-1}=10^{-3} \mathrm{~s}^{-1}\right)$, their relative weights $(\%)$, and cluster ion average lifetimes (s) during the whole measurement period.

\begin{tabular}{ccccccc}
\hline$+/-$ & h:m & Recombination sink & Aerosol sink & Forest sink & Total sink & Lifetime \\
\hline+ & 2 & $1.0 \mathrm{ks}^{-1} \sim 13 \%$ & $5.0 \mathrm{ks}^{-1} \sim 66 \%$ & $1.5 \mathrm{ks}^{-1} \sim 20 \%$ & $7.6 \mathrm{ks}^{-1}$ & $132 \mathrm{~s}$ \\
- & 2 & $1.2 \mathrm{ks}^{-1} \sim 13 \%$ & $6.2 \mathrm{ks}^{-1} \sim 69 \%$ & $1.6 \mathrm{ks}^{-1} \sim 18 \%$ & $9.0 \mathrm{ks}^{-1}$ & $110 \mathrm{~s}$ \\
+ & 14 & $0.7 \mathrm{ks}^{-1} \sim 9 \%$ & $5.1 \mathrm{ks}^{-1} \sim 65 \%$ & $2.0 \mathrm{ks}^{-1} \sim 26 \%$ & $7.9 \mathrm{ks}^{-1}$ & $127 \mathrm{~s}$ \\
- & 14 & $0.8 \mathrm{ks}^{-1} \sim 9 \%$ & $6.3 \mathrm{ks}^{-1} \sim 69 \%$ & $2.1 \mathrm{ks}^{-1} \sim 23 \%$ & $9.2 \mathrm{ks}^{-1}$ & $109 \mathrm{~s}$ \\
\hline
\end{tabular}

Additional products of the solution of Eqs. (21) are the estimates of the particle mean charge and the space charge density of the air in Table 4 . At the height of $2 \mathrm{~m}, 71 \%$ of the space charge is carried by aerosol particles and $29 \%$ by cluster ions. At the height of $14 \mathrm{~m}$ the proportions are $84 \%$ and $16 \%$. The average space charge density on the level of the tops of trees is about $440 \mathrm{e} \mathrm{cm}^{-3}$, which is a little higher than the typical values of the space charge density near the ground (Israël, 1973). We are not aware of earlier measurements of the space charge on the level of treetops over a forest. The well-known negative correlation of the space charge density with the turbulent diffusion is a probable explanation of the relatively high value recorded in the present experiment. The space charge density of $440 \mathrm{e} \mathrm{cm}^{-3}$ creates the vertical gradient of the electric field about $8 \mathrm{~V} \mathrm{~m}^{-1}$. The gradient of the vertical electric field is an attribute of the near ground electrode effect, a well-known phenomenon in atmospheric electricity (Israël, 1970, 1973; Willett, 1985). As a result the electric field can be doubled immediately near the conductive surface. The average electric field over the ground in fair weather situation at the latitude of $60^{\circ}$ is about $160 \mathrm{~V}$ $\mathrm{m}^{-1}$ (Israël, 1973). This corresponds to the vertical scale of the electrode effect layer over the tops of trees at about $10 \mathrm{~m}$, which is consistent with the known models developed in research on atmospheric electricity. However, it should be kept in mind that the uncertainty of the space charge density calculated according to Eq. (21) can exceed $200 \mathrm{e} \mathrm{cm}^{-3}$ and the numbers above should be considered as rough estimates.

The estimates of specific sinks and the average lifetime of cluster ions according to the measurements are presented in Table 6. These estimates show that the forest sink makes up on average about one third of the cluster ion losses in the Hyytiälä forest.

\section{Conclusions}

The proposed theoretical model of cluster ion balance in coniferous forest includes the sink of cluster ions due to the dry deposition on the forest canopy, which has been neglected in earlier models. The parameters describing positive and negative ions are assumed to be different. The model yields simple equations, which allow calculating the esti- mates of the ionization rate and the space charge density of the air according to the measurements of cluster ion concentrations and mean mobilities, aerosol particle concentration and mean diameter, parameters of the forest, air temperature, pressure, and wind speed. The forest is described by two parameters: the overall length of the needles in a unit volume and the average diameter of the needles. The applications of the model are limited to periods without nucleation bursts.

The atmospheric electric field is neglected in the model because of its small effect, which is proven by nearly identical values of the positive to negative cluster ion concentration ratio near the tops of the trees and below the forest canopy, where the atmospheric electric field is shielded.

The proposed method does not amplify the measurement errors when estimating the ionization rate. The errors of some arguments like air pressure, recombination coefficient and wind speed are even effectively suppressed. Unfortunately, the coefficients of the transfer of the errors from cluster ion measurements to the estimates of particle mean charge and air space charge density appear to be fairly large and the standard deviation of the estimated particle mean charge is about half of its typical value.

The average cluster ion concentrations near the ground inside the Scots pine forest in Hyytiälä, Finland, are considerably higher than between the tops of the pines. This is explained by the increased ionization rate. The vertical gradient of the cluster ion concentrations decreases with the intensification of the vertical mixing of the air. The average ionization rate at the height of $2 \mathrm{~m}$ proved to be $5.6 \mathrm{~cm}^{-3} \mathrm{~s}^{-1}$ and at the height of $14 \mathrm{~m} 3.9 \mathrm{~cm}^{-3} \mathrm{~s}^{-1}$. These values are a little lower than the average $6.6 \mathrm{~cm}^{-3} \mathrm{~s}^{-1}$ found by Tuomi (1989) in a suburb of Helsinki, and similar to the value of $4.5 \mathrm{~cm}^{-3} \mathrm{~s}^{-1}$ found by Laakso et al. (2004b) in Hyytiälä according to the measurements of ionizing radiations, but considerably higher than the value of $2.6 \mathrm{~cm}^{-3} \mathrm{~s}^{-1}$ calculated in the same study according to the air ion measurements. Systematic factors of the difference in results are the neglect of the dry deposition on the forest canopy and the underestimation of the mobility of cluster ions in the earlier study. These factors give a sufficient explanation for the internal controversy of the earlier estimates and the controversy with the results of the present study. 
As an average the recombination sink of cluster ions on the ions of opposite polarity makes up $9-13 \%$, the sink on aerosol particles 65-69\%, and the sink on forest canopy 18$26 \%$ of the total sink. The average lifetime of cluster ions proved to be about $130 \mathrm{~s}$ for positive ions and about $110 \mathrm{~s}$ for negative ions during the measurements. The available data are not sufficient to quantitatively explain the differences in the ionization rates at the two heights of $2 \mathrm{~m}$ and $14 \mathrm{~m}$. Some part of the difference may be caused by the accumulation of radon near the ground, especially during the nocturnal calm. Additionally, a hypothesis is advanced that a part of air ions is produced by the alpha radiation, which is emitted by the radon daughters deposited onto the conifer needles and the forest undergrowth. The height variation should be considered when the ionization rate is used as a parameter in the models of ion-induced nucleation. Additional products of the calculations according to the new model are the estimates of the space charge density of the air and its fraction carried by particles. The average space charge density on the level of the tops of trees proved to be about $440 \mathrm{e} \mathrm{cm}^{-3}$. The space charge is carried mostly by the aerosol particles: $71 \%$ at the height of $2 \mathrm{~m}$ and $84 \%$ at the height of $14 \mathrm{~m}$.

The presented results are based on short-term measurements and are not verified with simultaneous measurements using different methods. Thus the conclusions have a provisional character and additional measurements are required for better understanding of the air ion height variation in the forest.

\section{List of symbols}

$\alpha \quad$ Cluster ion recombination coefficient

$\beta \quad$ Cluster ion combination or attachment coefficient

$\gamma$ Coefficient of unipolarity of cluster ion polar conductivities

$\varepsilon_{o} \quad$ Electric constant $8.85 \times 10^{-12} \mathrm{~F} \mathrm{~m}^{-1}$

$v$ Kinematic viscosity of air

$\rho \quad$ Space charge density of air

$c$ Correction coefficient in the equation of

the aerosol sink of clusterions

$d_{n} \quad$ Diameter of conifer needles

$d_{p} \quad$ Mean diameter of background aerosol particles

$d_{q}$ Characteristic length of the Coulomb attachment

$D$ Diffusion coefficient of cluster ions

$e \quad$ Elementary charge, $1.6 \times 10^{-19} \mathrm{C}$

$h \quad$ Height from the ground

I Ionization rate

$k \quad$ Boltzmann constant, $1.38 \times 10^{-23} \mathrm{~J} \mathrm{~K}^{-1}$

$L_{n} \quad$ Average density of needle lengths in forest canopy

$n \quad$ Number concentration of cluster ions

$N$ Number concentration of aerosol particles

$N_{f}$ Equivalent number concentration expressing cluster ion depletion in the forest

$p \quad$ Atmospheric pressure

$q \quad$ Number of elementary charges

$q_{p} \quad$ Algebraic mean number of elementary charges on a particle

$s_{c} \quad$ Recombination sink of cluster ions

$s_{p} \quad$ Aerosol sink of cluster ions

$s_{f} \quad$ Forest sink of cluster ions

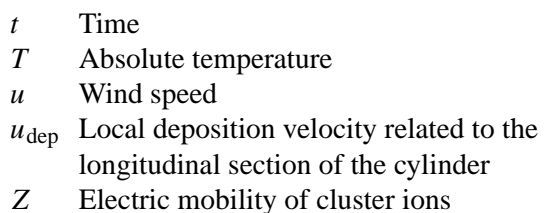

Acknowledgements. This work was supported by the Estonian Science Foundation under grant no. 6223 and by the EU project QUEST. The authors thank P. P. Aalto for providing the aerosol and meteorological data and A. Hirsikko for discussions.

Edited by: N. Lovejoy

\section{References}

Chen, J. M., Rich, P. M., Gower, S. T., Norman, J. M., and Plummer, S.: Leaf area index of boreal forests: theory, techniques, and measurements, J. Geophys. Res.-Atmos., 102, 29429-29443, 1997.

Clement, C. F. and Harrison, R. G.: The charging of radioactive aerosols, J. Aerosol Sci., 23, 481-504, 1992.

Crozier, W. D. and Biles, N.: Measurements of radon 220 (thoron) in the atmosphere below 50 centimeters, J. Geophys. Res., 71, 4735-4741, 1966.

Dhanorkar, S. and Kamra, A. K.: Diurnal variation of ionization rate close to ground, J. Geophys Res., 99, 18 523-18 526, 1994.

Dhanorkar, S. and Kamra, A. K.: Effect of coagulation on the asymmetric charging of aerosols, Atmos. Res., 66, 159-173, 2003.

Fuchs, N. A.: On the stationary charge distribution on aerosol particles in a bipolar ionic atmosphere, Geofis. pura e appl., 56, 185193, 1963.

Harrison, R. G. and Carslaw, K. S.: Ion-aerosol cloud processes in the lower atmosphere, Rev. Geophys., 41, 3/1013, doi:10.1029/2002RG000114, 2003.

Hess, V. F.: Neue Untersuchungen über die Ionisierungsbilanz in der Atmosphäre auf Helgoland, Gerl. Beitr. Geophys., 22, 256314, 1929.

Hirsikko, A., Laakso, L., Hõrrak, U., Aalto, P. P., Kerminen, V.M., and Kulmala, M.: Annual and size dependent variation of growth rates and ion concentrations in boreal forest, Boreal Env. Res., 10, 357-369, 2005.

Hoppel, W. A., Anderson, R. V., and Willett, J. C.: Atmospheric electricity in the planetary boundary layer, in: The Earth's electrical environment, National Academy Press, Washington D.C., 149-165, 1986a.

Hoppel, W. A. and Frick, G. M.: Ion-aerosol attachment coefficients and steady-state charge distribution on aerosols in a bipolar ion environment, Aerosol Sci. Technol., 5, 1-21, 1986 b.

Hõrrak, U., Salm, J., and Tammet, H.: Statistical characterization of air ion mobility spectra at Tahkuse Observatory: Classification of air ions, J. Geophys. Res.-Atmos., 105, 9291-9302, 2000.

Hõrrak, U., Salm, J., and Tammet, H.: Diurnal variation in the concentration of air ions of different mobility classes at a rural area, J. Geophys. Res.-Atmos., 108(D20), 4653, doi:10.1029/2002JD003240, 2003.

Hõrrak, U., Aalto, P. P., Salm, J., Mäkelä, J. M., Laakso, L., and Kulmala, M.: Characterization of air ions in boreal forest air during BIOFOR III campaign, Atmos. Chem. Phys. Discuss., 5, 
2749-2790, 2005,

http://www.atmos-chem-phys-discuss.net/5/2749/2005/.

Incropera, F. P. and Dewitt, D. P.: Fundamentals of Heat and Mass Transfer, Fifth Edition, Wiley, New York, 944, 2002.

Israël, H.: Atmospheric electricity, vol. I, Israel Program for Sci. Transl. \& NSF, Jerusalem, 328, 1970.

Israël, H.: Atmospheric electricity, vol. II, Israel Program for Sci. Transl. \& NSF, Jerusalem, 502, 1973.

Kulmala, M., Hämeri, K., Aalto, P. P., Mäkelä, J. M., Pirjola, L., Nilsson, E. D., Buzorius, G., Rannik, Ü., dal Maso, M., Seidl, W., Hoffman, T., Janson, R., Hansson, H.-C., Viisanen, Y., Laaksonen A., and O'Dowd, C. D.: Overview of the international project on biogenic aerosol formation in the boreal forest: BIOFOR, Tellus, 53B, 324-343, 2001.

Kulmala, M.: How particles nucleate and grow, Science, 302, 10001001, 2003.

Kulmala, M., Vehkamäki, H., Petäjä, T., Dal Maso M., Lauri, A., Kerminen, V.-M., Birmili, W., and McMurry, P. H.: Formation and growth rates of ultrafine atmospheric particles: A review of observations, J. Aerosol Sci., 35, 143-176, 2004.

Laakso, L., Mäkelä, J. M., Pirjola, L., and Kulmala, M.: Model studies on ion-induced nucleation in the atmosphere, J. Geophys. Res.-Atmos., 107(D20), 4427, doi:10.1029/2002JD002140, 2002.

Laakso, L., Anttila, T., Lehtinen, K. E. J., Aalto, P. P., Kulmala, M., Hõrrak, U., Paatero, J., Hanke, M., and Arnold, F.: Kinetic nucleation and ions in boreal forest particle formation events, Atmos. Chem. Phys., 4, 2353-2366, 2004a.

Laakso, L., Petäjä, T., Lehtinen, K. E. J., Kulmala, M., Paatero, J., Hõrrak, U., Tammet, H., and Joutsensaari, J.: Ion production rate in a boreal forest based on ion, particle and radiation measurements, Atmos. Chem. Phys., 4, 1933-1943, 2004b.

Nagaraja, K., Prasad, B. S. N., Madhava, M. S., Chandrasekara, M. S., Paramesh, L., Sannappa, J., Pawar, S. D., Murugavel, P., and Kamra, A. K.: Radon and its short-lived progeny: variations near the ground, Radiation measurements, 36, 413-417, 2003.

Rannik, Ü., Aalto, P., Keronen, P., Vesala, T., and Kulmala, M.: Interpretation of aerosol particle fluxes over a pine forest: Dry deposition and random errors, J. Geophys. Res.-Atmos., 108(D17), 4544, doi:10.1029/2003JD003542, 2003a.
Rannik, Ü., Markkanen, T., Raittila, J., Hari, P., and Vesala, T.: Turbulence statistics inside and over forest: influence of footprint prediction, Boundary-Layer Meteorol., 109, 163-189, 2003b.

Seinfeld, J. H. and Pandis, S. N.: Atmospheric chemistry and physics, From air pollution to climate change, Wiley, New York, 1998.

Svensmark, H.: Influence of cosmic rays on Earth's climate, Phys. Rev. Lett., 81, 5027-5030, 1998.

Tammet, H.: Size and mobility of nanometer particles, clusters and ions, J. Aerosol Sci., 26, 459-475, 1995.

Tammet, H.: Balanced Scanning Mobility Analyzer, BSMA, in: Nucleation and Atmospheric Aerosols, Kyoto, 294-297, 2004.

Tammet, H.: Continuous scanning of the mobility and size distribution of charged clusters and nanometer particles in atmospheric air and the Balanced Scanning Mobility Analyzer BSMA, Atmos. Res., in press, doi:10.1016/j.atmosres.2006.02.009, 2006.

Tammet, H. and Kimmel, V.: Electrostatic deposition of radon daughter clusters on the trees, J. Aerosol Sci., 29, S473-S474, 1998.

Tammet, H. and Kulmala, M.: Simulation tool for atmospheric aerosol nucleation bursts, J. Aerosol Sci., 36, 173-196, 2005.

Tammet, H., Kimmel, V., and Israelsson, S.: Effect of atmospheric electricity on dry deposition of airborne particles from atmosphere, Atmos. Environ., 35, 3413-3419, 2001.

Tuomi, T. J.: Ten year summary 1977-1986 of atmospheric electricity measured at Helsinki-Vantaa airport, Finland, Geophysica, 25, 1-20, 1989.

Wesely, M. L. and Hicks, B. B: A review of the current status of knowledge on dry deposition, Atmos. Environ., 34, 2261-2282, 2000.

Willett, J.: Atmospheric-electric implications of ${ }^{222} \mathrm{Rn}$ daughter deposition on vegetated ground, J. Geophys. Res., D90, 59015908, 1985.

Yu, F. and Turco, R. P.: From molecular clusters to nanoparticles: The role of ambient ionization in tropospheric aerosol formation, J. Geophys. Res.-Atmos., 106, 4797-4814, 2001.

Zhou, J.: Hygroscopic properties of atmospheric aerosol particles in various environments, $\mathrm{PhD}$ thesis, University of Lund, Division of Nuclear Physics, Sweden, 166, 2001. 